\title{
Analisis Karakter Panda sebagai Model Desain pada T-Shirt Electrica Panda Artwear Medan
}

\section{Character Analysis of Panda as a Design Model in T-Shirt Of Electrica Panda Artwear Medan}

\author{
Iqbal Mudri Khatikno* \& Raden Burhan SND* \\ Program Studi Pendidikan Seni Rupa, Jurusan Seni Rupa Fakultas Bahasa Dan Seni \\ Universitas Negeri Medan, Indonesia
}

Diterima: 25 September 2020; Direview: 26 September 2020; Disetujui: 17 Oktober 2020

*Coresponding Email: iqbalmudry@gmail.com, radhenboerhans@gmail.com

\begin{abstract}
Abstrak
Penelitian ini bertujuan untuk mendeskripsikan kecenderungan warna dan teknik serta prinsip desain karakter panda pada $t$-shirt Electrica Panda. Penelitian ini difokuskan kepada ketujuh aspek yang menjadi dasar penelitian ini yaitu aspek keseimbangan, penekanan, irama, kesatuan, proporsi, teknik dan warna. Teknik pengumpulan data pada penelitian ini dilakukan dengan teknik observasi, wawancara serta dokumentasi. Data dianalisis dengan teknik analisis deskriptif, yaitu mendeskripsikan keseimbangan, penekanan, irama, kesatuan, proporsi, teknik dan warna yang digunakan pada desain $t$ shirt produksi Electrica Panda Artwear di kota Medan. Hasil penelitian ini sebagai yaitu; Pada desain $t$ shirt Electrica Panda Artwear, menggunakan keseimbangan yang bervariasi; penekanan yang berbeda pada tiap desainnya; irama berbeda tiap desainnya; memiliki kesatuan yang harmonis dari keseluruhan desain; menggunakan penekanan yang berbeda sesuai desain yang dibuat; menggunakan teknik digital yang kemudian proses sablon gambar secara manual; serta menggunakan beragam warna yang memicu makna desain lebih jelas.
\end{abstract}

Kata kunci: Prinsip Desain Karakter; T-shirt; Electrica Panda

\begin{abstract}
The aim of this study is to describe the tendency of colours and techniques as well as design principles of panda character used in Electrica Panda t-shirt. This study was focused on seven fundamental parameters, namely balance, emphasis, rhythm, unity, proportion, technique, and colour. The data was collected using observational, interview, and documentation methods. The data was analysed using descriptive analysis, which describes the balance, emphasis, rhythm, unity, proportion, technique, and colour used in $t$-shirt design of Electrica Panda Artwear Medan production. The results of the study are; in the design of Electrica Panda Artwear, the balance used was varied; design used was varied; there was different emphasis used in each design; the rhythm used in each design was different; all designs used were harmonious; the proportions applied were varied based on the blueprint; the drawing techniques used were digital technique and followed by a manual Sablon painting process; as well as the colours employed were diverse which leads to a clear meaning of the design.
\end{abstract}

Keywords : Design, T-shirt, and Panda

How to Cite: Khatikno, I.M \& Burhan, R (2020). Analisis Karakter Panda Sebagai Model Desain T-Shirt Electrica Panda Artwear Medan. Journal of Education, Humaniora and Social Sciences (JEHSS). 3(2): 552-559. 


\section{PENDAHULUAN}

Pada awalnya t-shirt yang dikenal dengan sebutan kaos oblong bukanlah bagian dari dunia fashion. T-shirt hanya digunakan sebagai baju dalam para anggota U.S Navy untuk melindungi bulu dada mereka. Ada beberapa pabrik yang kemudian mulai membuatnya sebagai produk yang lebih massal, tetapi itu belum menjadi sebuah pakaian pantas sehari-hari (Fresner, 1995).

Seiring dengan perkembangannya t-shirt digunakan sebagai medium pengantar pesan visual. Medium ini benar-benar dimanfaatkan secara maksimal hingga penggambaran dan penyampaiannya dibentuk semenarik mungkin agar konsumen tertarik memiliki kaos tersebut. Kemudian, konsumen akan dengan bangga membeli t-shirt dengan logo sebuah produk yang sudah dikenal atau diminati banyak orang. Karena ketertarikannya, maka konsumen secara langsung membeli sekaligus mempromosikan produk tersebut secara sukarela.

Salah satu brand clothing yang cukup terkenal di Medan yaitu Electrica Panda Artwear. Brand yang berangkat dari kecintaan terhadap Panda menjadikan Panda adalah konsep utama dalam setiap desain yang di buat. Brand asal Medan yang berdiri sejak September 2013 ini memiliki toko yang yang berada di Jl. Gaperta No.206 serta dinamakan House Of Electrica Panda. Didirkan oleh : M. Rizki Saragih. Awal mula pembentukan brand ini berasal dari kegemarannya menggambar serta latar pendidikan yang merupakan lulusan D3 desain grafis Politeknik Negeri Media Kreatif Medan. Sehingga sebuah pemikiran dan keiginannya untuk meramaikan industri kreatif di kota Medan khususnya di bidang fashion semakin kuat. Hingga akhirnya, Electrica Panda Artwear hadir sebagai produk dengan warna baru di kota Medan. Dengan konsep yang diusung yaitu menghadirkan tema Panda yang dijadikan sebagai ciri khas dalam setiap produk yang dikemas dalam setiap edisinya. Electrica panda hadir sebagai kebutuhan fashion anak muda masa kini yang ceria, energik serta selalu kekinian dan berkembang mengikuti perkembangan zaman namun tetap idealis untuk menunjukkan ciri khas tersendiri. Dengan membawa misi "let's adop don't stop" yang mengartikan sebuah ajakan untuk para penikmat Electrica Panda Artwear untuk mengadopsi bukan membeli yang bermaksud agar terjadi ikatan emosional yang baik antara produk yang mereka jual dengan konsumen.

Electrica Panda sendiri sampai sekarang sudah memiliki 20 reseller yang terletak di berbagai kota besar indonesia. Tumbuh dan besar dengan mendukungberbagai acara event lokal, endorsement band lokal, aktif di berbagai komunitas sehigga terbentuk sebuah komunitas khusus Electrica Panda Artwear yang di sebut ETPD Team yang ada di kota-kota seluruh Indonesia.

Sebagai perbandingan, Kota Medan juga mempunyai brand yang sempat menjadi icon dari warga Medan. Tauko Medan contohnya, dari nama saja dapat di artikan sebagai kalimat tanya: tau kau Medan, sebuah kalimat tanya yang diucapkan dengan logat Batak (orang Medan biasa mengatakan kau dengan ko). Yang di simbolkan dengan lambang menara air PDAM Tirtanadi. Tauko Medan sudah lebih dahulu berdiri sejak 2006 dan sempat memiliki 2 outlet dikota Medan. namun seiring berkembangnya dunia fahsion mereka tidak mampu mengikuti perkembanganya, hingga masyarakat menilai desain yang hanya itu-itu saja serta hanya mampu tembus di pangsa lokal, inkonsistensi dalam desain t-shirt membuat jati diri Tauko Medan semakin hilang, dimana seperti kehilangan arah. Sehingga sejak tahun 2016 mereka menutup seluruh outlet yang ada di Kota Medan dan hanya menjual produk secara online. Secara keseluruhan Electrica Panda memiliki kelebihan di banding Tauko Medan, dimana Electrica Panda mampu mengikuti perkembangan fashion anak muda dan permintaan pasar di Indonesia serta konsisten dalam setiap desain t-shirt yang di keluarkan. Ini menjadikan mengapa Electrica Panda Artwear menarik untuk di bahas.

Permasalahan-permasalahan yang tertera di atas juga terlihat dari beberapa penelitian yang telah ada seperti penelitian yang pernah ditulis oleh Arifi, dkk (2014) dalam jurnal Pendidikan Seni Rupa yang berjudul "Tinjauan Desain Grafis Kaos Sablon Graffiti di Gardu House Jakarta". Mengemukakan bahwa penelitian ini ialah tentang bagaimana visualisasi desain, konsep desain, dan penerapan desain grafis pada kaos sablon graffiti di Gardu House Jakarta. Hasil penulisan dari penelitian ini terdapat beberapa manfaat yang diharapkan dapat tercapai, 
diantaranya yaitu dapat menambah informasi atau wawasan tentang desain grafis kaos pada umumnya dan kaos graffiti, dapat mengangkat citra Gardu House dalam dunia graffiti Indonesia pada khususnya, dan untuk lebih mengembangkan lagi kreatifitas dalam menciptakan rancangan desain grafis kaos graffiti di Gardu House. Adapun hasil penelitiannya menyatakan warna putih menjadi sangat dominan karena semua desain ini menggunakan warna tersebut. Garis yang digunakan pada desain-desain tersebut adalah garis horizontal, vertikal, diagonal, zig zag, dan lain-lain. Sedangkan untuk tipografi, rata-rata tipografi pada desain-desain tersebut tidak menggunakan jenis font yang terdapat dalam sistem operasional komputer, melainkan tipografi dekoratif yang dibuat secara manual oleh desainer. Rata-rata desain tersebut terletak di bagian depan kaos. Konsep desain tentang simbol-simbol graffiti dan jalanan sangat sering dipakai sebagai tema pada desain-desain kaos tersebut. Terdapat 7 desain yang menggunakan tema tentang graffiti dan jalanan. Dan dari 10 desain tersebut fungsi identitas lebih banyak digunakan dalam penerapannya. Rata-rata identitas yang dimaksud adalah identitas merk atau karakter yang dibuat oleh desainer. Terbukti 6 dari 10 desain tersebut menerapkan fungsi identitas, sedangkan sisanya menerapkan fungsi edukasi dan fungsi persuasi.

Penelitian ini memiliki persamaan yaitu memiliki tujuan untuk mengetahui karakter desain yang di pakai pada t-shirt. Adapun persamaan yang lainya terletak pada objek penelitiannya yaitu sama-sama menerapkan fungsi identitas. Pada penelitian Arifi, dkk subjeknya adalah visualisasi desain, konsep desain dan penerapan desain pada t-shirt, sedangkan pada penelitian ini subjeknya adalah karakter Panda, konsep desain dan penerapan desain pada t-shirt.

Pada penelitian tersebut juga dapat dilihat bahwa kreatifitas dalam menciptakan rancangan desain grafis kaos sudah cukup menarik, namun warna yang digunakan pada desain tshirt tersebut yang lebih dominan hanya warna putih saja, tiporafi yang digunakan juga hanya tipografi dekoratif yang dibuat secara manual oleh desainer.

Tidak hanya itu, terdapat juga penelitian yang mendukung beberapa penelitian yang ada seperti pada penelitian Abidin (2013) dalam jurnal Pendidikan Seni Rupa yang berjudul "Analisis dan Pengembangan Desain Kaos Distro Bonek Original di Ketintang Surabaya". Mengemukakan bahwa penelitiannya berisi tentang, 1) bagaimana bentuk desain kaos distro Bonek Original; 2) bagaimana pengembangan desain kaos distro Bonek Original menurut keinginan konsumen. Hasil penelitiannya yaitu peneliti mendeskripsikan bentuk desain kaos distro Bonek Original selama bulan Mei hingga Juli 2012 dan peneliti mengetahui keinginan konsumen distro Bonek Original. Kemudian peneliti membuat tiga desain baru dengan mengembangkan keinginan konsumen tersebut. Ketiga desain tersebut telah sesuai dengan keinginan konsumen saat ini.

Pada penelitian Abidin tersebut tampak bahwa objek yang diteliti hampir sama dengan objek yang ingin penulis teliti. Hal tersebut tampak pada penelitiannya membahas mengenai bentuk desain kaos distro Bonek Original, bentuk yang dijelaskannya pada penelitiannya tersebut mencakup aspek objek, tipografi dan tema yang diminati konsumen. Sedangkan pada penelitian ini jelas hanya membahas mengenai karakter Panda sebagai aspek objek, tema dan teknik. Maka dari itu penelitian Abidin akan sangat membantu pada penyelesaian penelitian ini.

Dengan susunan beberapa gambar yang terkandung di setiap desain T-shirt Electrica Panda Artwear ini menjadi menarik untuk di teliti dan diharapkan dengan adanya penelitian ini dapat membantu untuk mengetahui bagaimana penerapan prinsip desain pada karakter panda menjadikan T-shirt Electrica Panda Artwear digemari dan kenapa hewan panda yang di pilih. Berdasarkan gambaran latar belakang yang di paparkan diatas maka penulis tertarik melakukan penelitian dengan judul "Analisis Karakter Panda Sebagai Model Desain pada T-shirt Electrica Panda Artwear Medan"

\section{METODE PENELITIAN}

Untuk menjawab permasalahan yang ada dalam penelitian ini tentang "Analisis Karakter Panda Sebagai Model Desain pada T-shirt Electrica Panda Artwear Medan", maka metode yang akan dilakukan adalah pendekatan deskriptif dan teknik analisis kualitatif. Metode yang digunakan dalam penelitian ini adalah metode kulitatif, dan teknik pengumpulan data yang 
digunakan adalah observasi lapangan, dokumentasi, studi pustaka, dan wawancara terhadap narasumber. Penelitian dengan pendekatan kualitatif ini bersifat deskriptif, yaitu mengadakan pengamatan langsung pada objek penelitian terhadap 5 desain $t$-shirt yang menjadi sumber data, kemudian melakukan pengumpulan data dan informasi dengan melakukan kegiatan wawancara dengan narasumber dan kepustakaan melalui buku-buku, jurnal, ensiklopedia, sumber-sumber tertulis cetak, maupun penelitian terdahulu.

Adapun teknik analisis data pada penelitian ini memiliki langkah-langkah sebagai berikut:

- Pengumpulan data visual, dilakukan dengan cara tinjauan langsung kelapangan, mendokumentasikan data yang ada serta mengkelompokkan data yang ada menjadi beberapa bagian.

- Pengumpulan data verbal, dilakukan dengan cara mengambil data dari narasumber dengan cara memberikan angket kepada pemilik, pembeli dan pemakai.

- Reduksi data, dilakukan setelah Data ditemukan kemudian disusun, dikelompokkan serta diolah berdasarkan aspek objek, teknik dan warna pada desain $t$-shirt Electrica Panda Artwear.

- Validitas data, pada penelitian ini dilakukan dengan cara menguji kelayakan data tersebut berdasarkan analisis interpretasi, narasumber dan kajian pustaka.

\section{HASIL DAN PEMBAHASAN}

Electrica Panda Artwear memiliki ciri khas tersendiri yang menjadi identitas oleh brand tersebut. Identitas itu tampak dari tiap desain yang memang menggambarkan sebuah objek Panda dengan petirnya yang terletak di dahi panda tersebut. Setiap desain memiliki maksud dan tujuan tertentu sesuai dengan konsep desainnya. Maka, desain pada kaosini merupakan cara desainer memvisualisasikan atau mengajak konsumen untuk ikut membeli dan merawat $t$-shirt seperti mengadopsi panda.

Berdasarkan hasil penelitian dan pembahasan mengenaikarakter Panda sebagai model desain pada $t$-shirt Electrica Panda Artwear Medan ditinjau dari aspek keseimbangan, penekanan, irama, kesatuan, proporsi, teknik dan warna, pada 5 desain yang diteliti terdapat beberapa aspek yang memiliki kesamaan pada kelima desain tersebut. Yaitu aspek kesatuan dimana keseluruhan desain memiliki kesatuan yang harmonis, dan aspek teknik penggambaran dimana keseluruhan desain yang diteliti menggunakan teknik digital yang kemudian proses sablon gambar secara manual. Sedangkan dari aspek keseimbangan, penekanan, irama, proporsi, dan warna memiliki perbedaan tergantung dari desain yang dibuat. Hal ini bisa dilihat dari penjelasan berikut:

\section{DESAIN I}

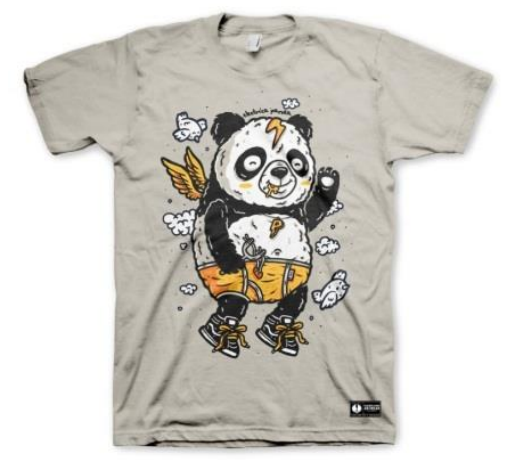

Gambar 1. Flying Panda

Sumber gambar: Dokumentasi Iqbal Mudri Khatikno

Berdasarkan keseimbangannya, penempatan objek karakter bayi panda berada di tengah sedangkan teks diletakkan bagian atas, tepatnya atas objek bayi panda, di tambah dengan objek 
pendukung seperti burung awan dan sepasang sayap sehingga tercipta keseimbangan elemen yang mendukung, hal ini memiliki kesan seimbang, dengan teks yang terdiri dari font Mesquite Std.

Sebagai point of interest atau penekanan pada karya ini adalah bentuk karakter anak panda. Hal ini dapat dilihat dari bentuk dan posisi desain anak panda tersebut yang berada ditegah dengan ukuran yang lebih besar dan mencolok disbanding objek lainya.

Pada desain flying panda unsur irama yang digunakan pada bentuk awan dan burung, sedangkan pada karakter utama tidak terjadi pengulangan, sehingga objek tambahan pada desain tersebut tidak mengganggu desain utama.

Proporsi pada desain ini sesuai dengan namanya "flying panda" karakter utama yang seolah terbang berada pada posisi tengah dan lebih besar dibandingkan dengan elemen pendukung lainya. Perbandingan ukuran dari bentuk keseluruhannya atau antara bentuk yang satu dengan yang lain tampak seimbang dan saling terhubung, sehingga membuat desain menjadi terlihat estetis. Hal ini sangat penting karena jika Proporsi yang tidak tepat, maka akan membuat sebuah karya menjadi tidak enak dipandang.

Pilihan warna t-shirt yang digunakan pada desain ini adalah grey (abu-abu), dengan kombinasi warna desain yang di dominasi putih hitam dan kuning menjadikan desain lebih jelas dan menojol sehingga lebih menarik perhatian.

\section{DESAIN II}

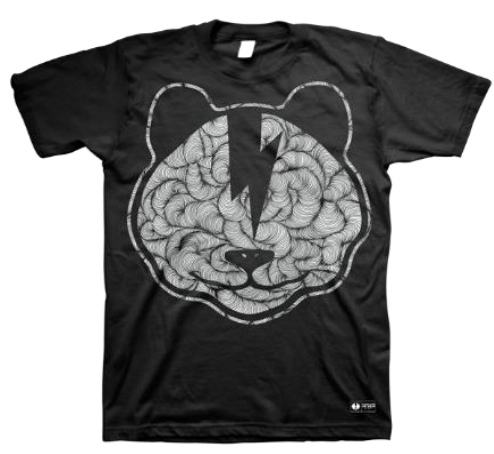

Gambar 2. Frequenz

Sumber gambar: Dokumentasi Iqbal Mudri Khatikno

Keseimbangan sering dikaitkan dengan satu kesatuan antar objek satu dengan objek yang lain. Karena objek gambar panda tersebut memilik bobot yang sama secara garis vertikal, sederhana dan seimbang.

Pada desain ini objek berada ditengah, sehingga saat mata melihat desain tersebut, pengamat akan langsung terfokus pada logo desain. Maka penekanan pada desain ini tampak dari wujud siluet kepala panda yang di isi dengan bentuk gelombang frekuensi.

Desain yang dibuat merupakan pengulangan satu atau lebih secara teratur dan terus menerus sehingga memiliki kesan menarik. Misalnya pada penggambaran ini menggunakan pengulangan pada unsur garis. Pengulangan pada unsur garis, jika dilakukan pada tempat yang tepat akan terlihat indah. Sehingga, pada desain ini dibuat dengan irama yang lebih harmonis agar menghasilkan nilai estetika yang unik dan dapat menarik perhatian penikmatnya.

Pada desain ini proporsi desain berada di tengan yang hampir menutupi seluruh area depan. Karena proporsi ini bertanggung jawab membandingkan bagian satu dengan bagian yang lain agar terlihat selaras dan enak dipandang. Untuk besar desain dengan media yang digunakan kiranya sudah cukup, tidak terlalu besar dan tidak terlau kecil jika dilihat dari sederhananya desain yang dibuat.

Desain ini menggunakan warna yang monokrom. Yaitu hitam dan putih. Walaupun menggunakan warna kontras yang bertentangan atau berlawanan, desain ini terasa lebih 
memiliki emosi. Dengan penggunaan warna monokrom ini, tentunya pembaca atau pengamat bisa melihat sebuah tampilan warna pada sebuah desain karena akan terlihat lebih jelas. Hal ini mungkin karena warna yang digunakan adalah warna yang senada dan selaras. Karena selain bentuk, dalam pewarnaan desain pun harus dapat disesuaikan dengan media yang digunakan.

\section{DESAIN III}
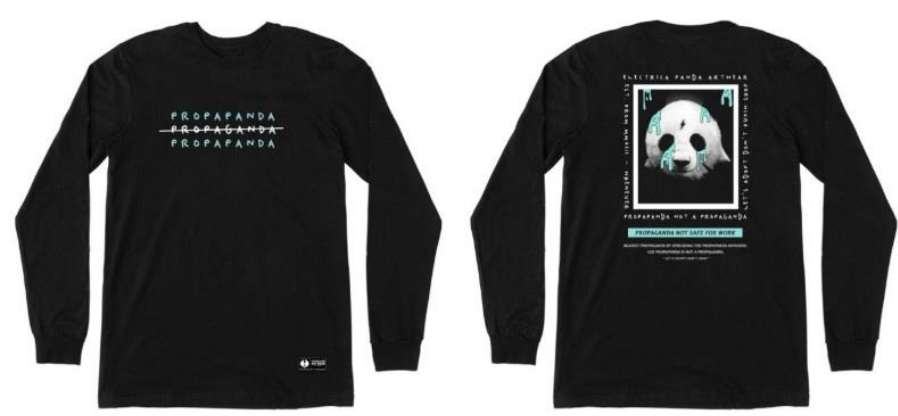

Gambar 3. Panda x 2.0

Sumber gambar: Dokumentasi Iqbal Mudri Khatikno

Salah satu keseimbangan pada desain ini dapat dilihat dari tulisan yang ada pada bagian depan $t$-shirt, terdapat terdapat 3 baris teks yang berada di tengah kaos, dan pada bagian belakang posisi gambar panda juga berada ditengah tetapidi kelilingi dengan tulisan tulisan secara vertikal dan horizontal. Posisi ini membuat desain terasa simbang tidak berat kekanan atau kekiri.

Sebagai point of interest pada karya ini ada dua penekanan, yang pertama di bagian depan dengan teks campaign yang berjumlah tiga baris dan bagian belakang dengan ilustrasi panda berumpur yang di kelilingi teks-teks slogan dari Electrica Panda.

Pengulangan tulisan pada desain bagian depan $t$-shirt menampilkan irama yang harmonis. Untuk desain bagian belakang terdapat pola gambar seperti lelehanyang menampilkan irama yang sama untuk sisi kanan dan sisi kirinya, begitu juga dengan tulisan yang ada pada sekeliling bingkai tersebut, memiliki irama yang sama setiap sisinya.

Proporsi pada desain ini terlihat estetik. Ukuran tulisan seimbang dengan ukuran $t$-shirt tersebut. Dimana desainya tidak terlalu dekat dengan kerah baju dan untuk tulisan di bagian belakang $t$-shirt tidak terlalu kebawah dan juga tidak terlalu kecil. Gambar panda sebagai maskot di brand ini sengaja di tampilkan dengan ukuran proporsi lebih besar dari bentuk desain lainnya.

Pilihan warnat-shirt yang digunakan adalah hitam, dengan kombinasi warna desain yang di dominasi putih dan hijau tosca. Menjadikan desain lebih jelas dan kontras antara warna kaos dan warna desain.

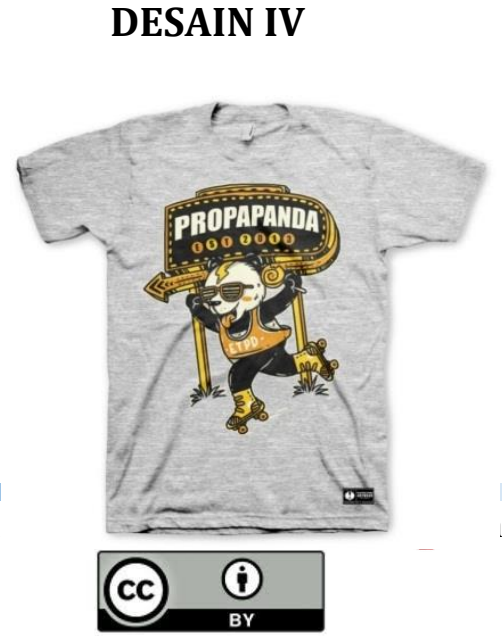




\title{
Gambar 4. Roll Out
}

Sumber gambar: Dokumentasi Iqbal Mudri Khatikno

Keseimbangan pada desain ini bisa dilihat dari elemen yang ada pada bagian depan $t$-shirt dimana yang pasti ada seekor panda yang sedang bermain sepatu roda ditambah dengan ekspresi ceria serta objek pendukung seperti papan iklan yang menabah kesan seimbang satu dengan yang lain dalam desain ini.

Point of interest pada karya ini adalah karakter panda yang sedang bermain sepatu roda. Hal ini dapat dilihat dari bentuk dan posisi panda tersebut berada ditegah dengan ukuran yang lebih besar dan mencolok disbanding objek lain pada desain ini. Irama pada desain ini terjadi pada warna sedangkan pada bentuk tidak terdapat pengulangan.

Proporsi karakter utama berada pada posisi tengah dan lebih besar dibandingkan dengan unsur-unsur pendukung lainya. Perbandingan ukuran dari bagian-bagian bentuk keseluruhannya atau antara bentuk yang satu dengan yang lain tampak seimbang, sehingga terlihat menarik.

Pilihan warna $t$-shirt yang digunakan adalah abu-abu, dengan kombinasi warna desain yang di dominasi putih hitam dan kuning menjadikan desain lebih jelas dan lebih terlihat menarik perhatian. Warna kuning pada desain ini sangat berperan baik, dan menimbulkan kesan hidup dan ramai pada gambar.

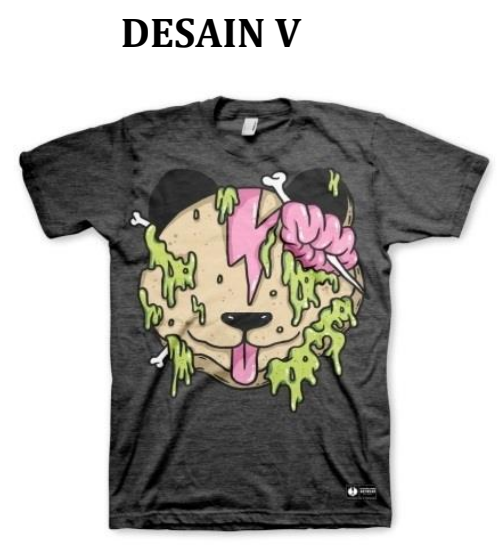

\author{
Gambar 5. Slimy Head \\ Sumber gambar: Dokumentasi Iqbal Mudri Khatikno
}

Pada desain ini terlihat pada penempatan objek utama berupa karakter imajinasi yang digabungkan dengan elemen seperti lendir madu danjarum yang tertusuk pada bagian kepala memberikan kesain simbang antara obek satu dengan objek lainya.

Desain yang diambil pada T-shirt berikut merupakan karakter kepala panda yang berdasar pada logo Electrica Panda. Penekanan jusrtu terdapat pada objek pendukung seperti lendir dan jarum yang tertusuk karena warna yang mencolok. menyatu.

Pada desain ini, objek kepala panda memiliki irama antara warna desain dan kaos yang

Karakter kepala panda tampak berada ditengah dengan ukuran yang cukup besar. Adanya seperti bentuk lendir disekeliling wajah panda tidak terlalu mengganggu karena bentuk lendir itu tersebar. Jarum yang tertancap di bagian kanan dan kirimemberi proporsi pada desain ini terlihat seimbang.

Warna kepala panda beserta tambahan objek lain disekelilingnya dikombinasi dengan $T$ shirt berwarna abu gelap tampak selaras. Perpaduan warna lendir yang hijau dengan otak berwarna pink dan tusukan jarum yang membuat gambar terlihat dramatis sangat menarik.

Dari keseluruhan desain yang telah diteliti maka terlihat banyak sekali variasi serta perbedan dari desain yang telah diciptakan. Electrica Panda Artwear hadir dengan konsisten membentuk berbagai produk yang tetap berfokus menjadikan Panda sebagai objek gambarnya. 
Desain yang diciptakan memerlukan imajinasi dan kreativitas dari desainer agar produk yang dipasarkan mampu bersaing dengan brand-brand lainnya.

Pada dasarnya proses pemasaran memerlukan strategi yang kuat agar minat dan ketertarikan konsumen pada kaos ini sangat kuat. Untuk itu, Electrica Panda Artwear masih terus membangun ikatan emosi pada konsumen dengan cara memberikan respon positif kepada konsumen. Sehingga konsumen yang merasa puas akan layanan penjual akan berkontribusi menawarkan dan membincangkan brand tersebut kepada orang disekitarnya. Serta melakukan beberapa trobosan baru yang melibatkan konsumen melalui media sosial seperti Instagram dan facebook sehingga dialog pecinta brand tersebut dengan produsen terjalin baik. Hal itulah yang membuat Electrica Panda Artwear masih banyak digemari masyarat hingga saat ini.

\section{SIMPULAN}

Dari keseluruhan desain yang telah diteliti maka terlihat banyak sekali variasi atau perbedan dari desain yang telah diciptakan. Walau begitu tetap ada persamaan antara desain yang satu dengan desain lainnya. Electrica Panda Artwear hadir dengan konsisten membentuk berbagai produk yang tetap berfokus menjadikan Panda sebagai objek gambarnya. Desain yang diciptakan memerlukan imajinasi dan kreativitas dari desainer agar produk yang dipasarkan mampu bersaing dengan brand-brand lainnya.

\section{DAFTAR PUSTAKA}

Abidin, V.Y.A. (2013). Analisis dan Pengembangan Desain Kaos Distro Bonek Original di Ketintang Surabaya. Surabaya: Jurnal Pendidikan Seni Rupa. Vol. 01 No. 01 tahun 2013. Hal. 91-99

Anindita, M., Menul, T.R. (2016). Tren Flat Design Dalam Desain Komunkasi Visual. Bogor:Dimensi DKV, Vo.1 No.(1)

Arifi, N.F. (2014). Tinjauan Desain Grafis Kaos Sablon Graffiti di Gardu House Jakarta. Yogyakarta. Surabaya: Jurnal Pendidikan Seni Rupa. Vol. 2 No. 2. Hal. 19-28

Arikunto, S. (2010). Prosedur Penelitian Suatu Pendekatan Praktik. Jakarta: PT. Rineka Cipta

Beazle, M. (2015). T-SHIRT Icons Of Style. New York : Octopus

Ferdinan, S.Y. (2015). Analisis Nilai Estetis Ilustrasi T-Shirt Tauko Medan Bertema Promosi Kota Medan. Medan: Skripsi Seni Rupa. Universitas Negeri Medan

Freshener, S. (1995). The T-Shirt Book.Gibbs Smith Publishing

Harahap, A.K. (2012). Representasi Karakter Masyarakat Kota Medan Dalam Desain Kaus Tauko Medan (Analisis Semiotika tentang Representasi Karakter Masyarakat Kota Medan dalam Desain Kaus Tauko Medan). Medan: e-Journal USU

Kusuma, W., dan Saputra, S.D. (2015). Pengaruh Desain Gambar, Merek Dan Kualitas Produk Kaos Terhadap Keputusan Pembelian Di Distro Idiomatic Yogyakarta. Jurnal Ekonomi Dan Kewiraushaan, Vol.15 No.(15) 275-282

Lintang, W. (2014). Teknik Arsir Dan Proses Menggambar Dengan Media Pena. Jurnal Humaniora, vol 5. No (2). (909-918)

Petrussumadi, A S. (1991). Dasar-dasar Desain. Jakarta: Depdikbud

Sembiring, D. (2014). Wawasan Seni. Medan: Unimed Press.

Sugiyono. (2014). Metode Penelitian (Pendekatan Kuantitatif, kualitatif, danR\&D). Bandung: Alfabet

Susilo, H. (2008). Tulisan Di T-Shirt Sebagai Gaya Hidup Remaja. Jurnal Ilmiah Bahasa Dan Sastra, Vol.4 No.(1)

Viatra, A.W. (2015). T-shirt Indieguerillas Sebagai Media Komunikasi Visual. Jurnal Seni Desain Dan Budaya, vol.2 No.(1) 